\title{
Analysis of Recrystallization Peak Occuring During DSC Measurement
}

\author{
Gergő Richárd FEJES¹, Viktor GONDA², Károly SZÉLL ${ }^{3}$ \\ ${ }^{1,2}$ Óbuda University, Donát Bánki Faculty of Mechanical and Safety Engineering, Institute of Materials and \\ Manufacturing Sciences, Department of Materials Technology, Budapest, Hungary \\ ${ }^{1}$ fejesgergorichard@gmail.com; ${ }^{2}$ gonda.viktor@bgk.uni-obuda.hu \\ ${ }^{3}$ Óbuda University, Alba Regia Mechanical Faculty, Székesfehérvár, Hungary
}

\begin{abstract}
Severe plastic deformation (SPD) is a well-established methodology for the processing of bulk ultrafine grained materials. Among various methods, equal channel angular pressing (ECAP) is the most popular way of creating ultrafine grained materials. The stored energy after ECAP in these substances highly influences the microstructural processes: recovery and recrystallization of the processed materials. We analyzed the recrystallization kinetics of room and elevated temperature ECAP processed copper samples using differential scanning calorimetry (DSC). For the processing of the measurement data we developed a MATLAB processing routine.
\end{abstract}

Keywords: ECAP, DSC, MATLAB, recrystallization, copper.

\section{Introduction}

Equal channel angular pressing (ECAP) is one of the severe plastic deformation (SPD) methods, by which grain refinement can be achieved in cold working, and bulk ultrafine grain materials can be produced. The large deformation induced during ECAP results in microstructural alterations. Grains are distorted and textured, dislocation density increases and saturates within the grains. Subsequently, dislocations pile up, and arrange in walls, thereby subgrains are formed and grain refinement occurs. Part of the energy introduced by the deformation is stored in the material in the dislocations; this energy is released by recrystallization and also acts as a driving force for recrystallization. This stored energy highly influences all kinds of microstructural transformations. In the present work - as a follow up to a prior study [1] -, ECAP was performed on electrolyte copper specimens at room temperature and at elevated temperatures. Thermal behaviour of the deformed samples was then examined by annealing in differential scanning calorimetry (DSC) equipment. During annealing, an exothermal peak arises at recrystallization in the DSC heat flux data, namely a recrystallization peak, which can be related to the stored energy released by the transformation. Prior to this, we analyzed manual processing methods of the peak to extract results. In the present work, we show results for recrystallization of ECAP processed samples at elevated temperatures, where the results were obtained by an automated data processing procedure of the DSC data created in MATLAB.

\section{Experimental procedures}

\subsection{Equal Channel Angular Pressing (ECAP)}

The material for ECAP processing was commercially available pure electrolyte copper in the form of extruded rods. Specimens were machined to a diameter of $10 \mathrm{~mm}$ and a length of 60 $\mathrm{mm}$. Prior to ECAP, specimens were annealed at $450^{\circ} \mathrm{C}$ for 1 hour.

ECAP processing was performed at several temperatures: room temperature, 50,100, 150, and $200^{\circ} \mathrm{C}$, with a feed of $8 \mathrm{~mm} / \mathrm{min}$ in an ECAP die with $110^{\circ}$ channel angle. Specimens were single pass processed, pressing forces were recorded 
during the deformations. To reduce friction, Molykote grease was employed, which is applicable from $-30^{\circ} \mathrm{C}$ to $1100^{\circ} \mathrm{C}$ temperature range.

After the deformations, at least 4 coin shaped samples were machined from each specimen for DSC, with a geometry of $\phi 5,9 \times 2,5(\mathrm{~mm})$ or $\phi 5,9 \times 1(\mathrm{~mm})$.

\subsection{Differential Scanning Calorimetry (DSC)}

For the thermal analysis, a Perkin-Elmer power compensated DSC-8000 was employed. In this equipment the heating power for linear heating of a specimen is controlled with a thermally neutral reference sample. The measured quantity is the power difference that is required for heating of the measurement and reference samples, and which can be plotted as a function of the temperature of time.

Annealing experiments were performed for the samples obtained at ECAP processing at room temperature, $50,100,150$, and $200^{\circ} \mathrm{C}$. Heating rates in the DSC measurements were $5,10,20$, and $50^{\circ} \mathrm{C} / \mathrm{min}$.

Samples were heated from room temperature to above the recrystallization temperatures, so that the transformation completed, in the first samples up to $400^{\circ} \mathrm{C}$, later based on the experiences up to $350^{\circ} \mathrm{C}$. Heat flux was recorded by the control software of the equipment, called Pyris, and the sampling rate was set to obtain about 10000 data points for each measurement. A set of measurement results is illustrated in Figure 1.

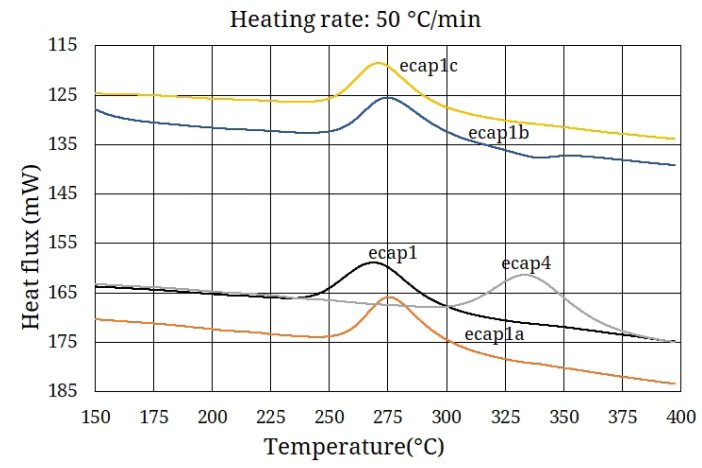

Figure 1. Heat flux recorded by DSC at a heating rate of $50^{\circ} \mathrm{C} / \mathrm{min}$ for the ECAP processed samples at different temperatures

\section{Data processing}

Due to the large number of recorded data points, an automated processing routine was required. The developed MATLAB processing routine requires minimal user interaction and provides quick, reliable results. Previously, we manually processed DSC data with the Pyris software, and also with the help Origin and Excel. We validated results obtained by the MATLAB routine with the manually processed data.

The MATLAB routine is controlled by a list of DSC data filenames, sample masses, and heat rates. These data are loaded into an array, then each data file in the list is processed. During the first stage of processing, the DSC data file is loaded, the measured data is plotted. Here, the program requires user interaction on the graphical interface, to point the onset and the end of the recrystallization peak. Then, the base line is determined by a 3rd order polynomial fitting, the goodness of fit can be visually inspected, and then the measurement data compensated by subtracting the base line. All properties of the peak are calculated subsequently and the results (to 3-digit precision) are stored in the tab separated text file. The resulting file contains: name of data, mass, heating rate, peak temperature, specific stored energy, and peak height. After the results are stored, a figure is created by a subroutine, plotting the compensated peak in a subtracted specific heat flow versus the temperature diagram, and labels the diagram with the most important calculated results (peak temperature, peak height, area under the peak stored energy) (Figure 2.). For each dataset, such figure is plotted and stored.

In the present dataset, each ECAP processing, contains four DSC samples. For this set, a processing routine generates a summary plot after four peaks are processed, from which differences due to the heating rates can be analyzed. This is then used for the determination of the activation energies of recrystallization.

Moreover, the program generates a figure about the fitted polynomial, the kinetics of the transformation as a function of the temperature. A detailed description of the program and its source code is available in [2].

The activation energy for recrystallization was calculated by the Kissinger theory [3].

\section{Results}

The analysis of the results of the processed DSC data for each of the ECAP processing temperatures helps to understand the thermal behavior of the highly deformed materials. To illustrate the analysis, we selected the results for the $5^{\circ} \mathrm{C} / \mathrm{min}$ heating rates from the measurement set. 


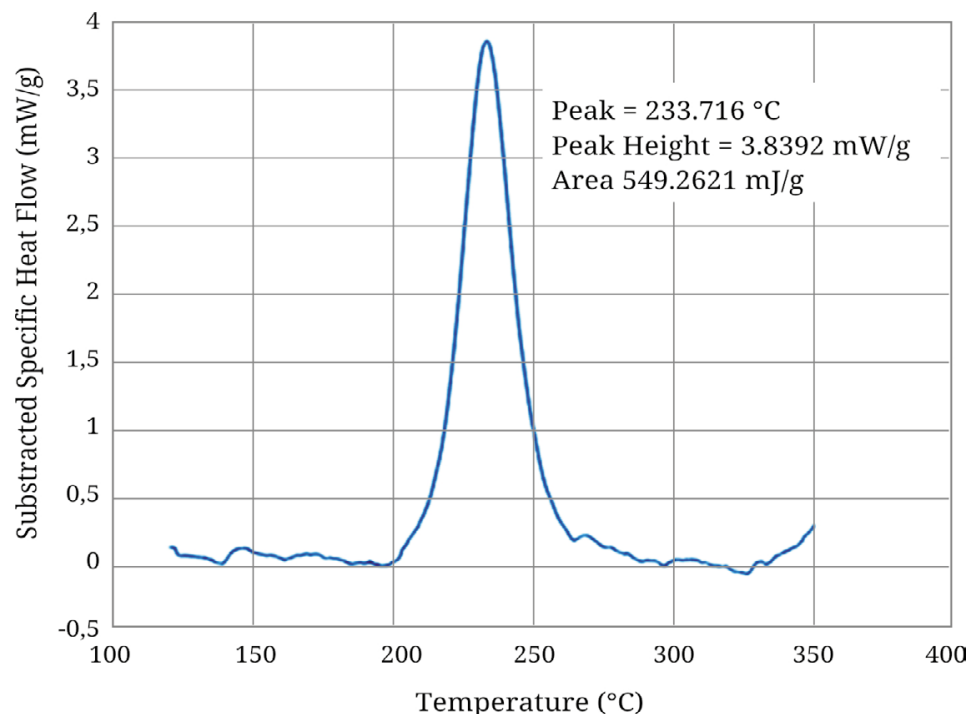

Figure 2. A plot of the compensated recrystalliza-tion peak with labels of the calculated peak properties

The peak temperatures, as a function of the ECAP processing temperature, is shown in Figure 3. It can be seen that the exothermic peak temperature, which marks the recrystallization transformation, steadily increases in the examined processing temperature range.

We can conclude by this observation that the increase in the deformation temperature - the energy required for initiating the recrystallization - also increases for the samples in different states.

The stored energy in the samples is released by recrystallization, the magnitudes are shown as a function of the ECAP processing temperature in Figure 4. The decrease in the stored energy shows that by increasing the processing temperature, less energy is stored in the dislocations of the material.

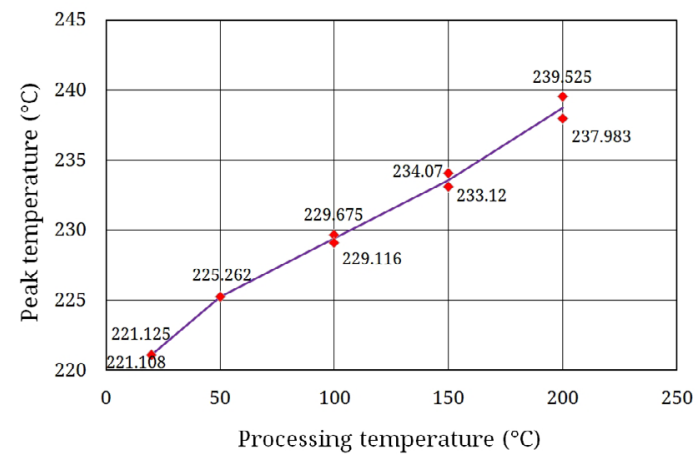

Figure 3. Recrystallization peak temperature as a function of the ECAP processing temperature.
The effect of the heating rates on a sample in a given state can be shown in the Arrhenius-plots, by which the activation energy can be determined. The variation of the activation energies as a function of the ECAP processing temperatures are shown in Figure 5.

By analyzing the activation energies, we can conclude that the activation energy is the lower at about $86 \mathrm{~kJ} / \mathrm{mol}$ at room temperature ECAP processing. The stored energy in the material was the highest in this case. With increasing processing temperature, as expected by the increasing peak temperatures and decreasing stored energies, activation energies increase slightly.

Based on these results we can conclude that the by increasing the ECAP processing temperature, the applied deformation energy is also lower, some transformation might already have occurred

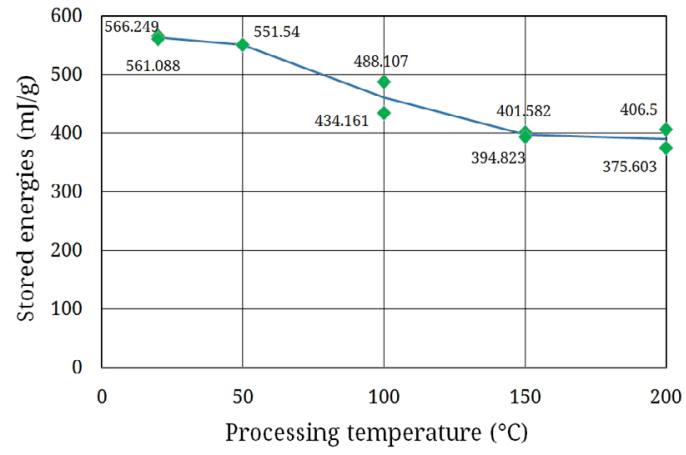

Figure 4. Stored energies as a function of the ECAP processing temperatures 
during the processing, the onset is delayed for recrystallization transformation, stored energy is decreased, and activation energy is slightly increased.

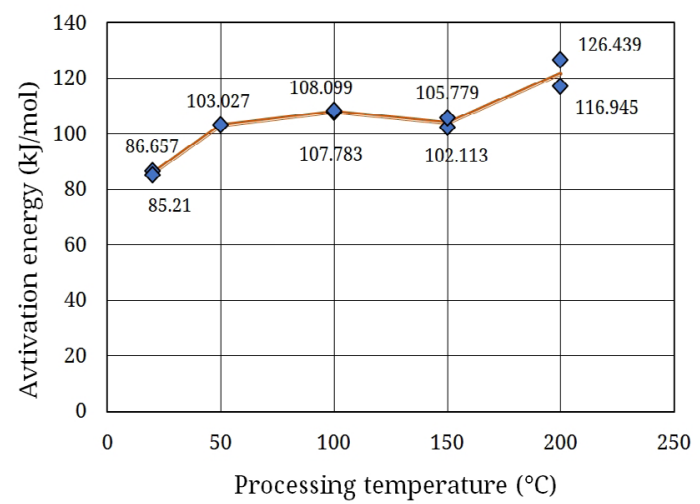

Figure 5. Activation energies as a function of the ECAP processing temperatures

\section{Acknowledgement}

This research was supported by EFOP-3.6.1-16-201600010.

\section{References}

[1] Fejes G. R., Gonda V.: Könyöksajtolt réz próbatestek DSC vizsgálata. In: A XXII. Fiatal müszakiak tudományos ülésszaka előadásai. Proceedings of the $22^{\text {th }}$ international scientific conference of youngth engineers, Cluj-Napoca, Romania, Müszaki Tudományos Közlemények 7. 2017. 151154.

https://eda.eme.ro/handle/10598/29768

[2] Fejes G. R.: Könyöksajtolt réz próbatestek DSC vizsgálata. In: XLV. Tudományos Diákköri Konferencia, Óbuda University, Budapest, 2017.

[3] Benchabane G., Boumerzoug Z., Thibon I., Gloriant T.: Recrystallization of pure copper investigated by calorimetry and microhardness. Materials Characterization, 59/10. (2008) 1425-1428.

https://doi.org/10.1016/j.matchar.2008.01.002 